\title{
Total synthesis of glycinoeclepin A
}

\author{
Akio Murai \\ Department of Chemistry, Faculty of science, \\ Hokkaido University, Sapporo 060, Japan
}

\begin{abstract}
A total synthesis of glycinoeclepin A, a natural hatching stimulus for the soybean cyst nematode, is described. The synthesis involves 32 steps and the overall yield is $0.4 \%$ from $(\underline{R})-(-)$-carvone. The hatch-stimulating activity of the synthetic sample was found to be indistinguishable from that of the natural sample.
\end{abstract}

\section{INTRODUCTION}

Glycinoeclepin A, isolated from the aqueous extracts of aried roots of kidney bean (Phaseolus vulgaris L.), is a natural hatching stimulus for the soybean cyst nematode (Heterodera glycines) (ref. 1). This compound stimulates the hatching and emergence of larvae in vitro in highly diluted aqueous solutions. The molecular structure ( 1 ) of the compound has been confirmed by the $x$-ray diffraction analysis (ref. $\overline{2}$ ). The highly biological importance and the unusual skeletal array of 1 as well as the lack of a satisfactory natural amount have prompted us to invëstigate the chemical synthesis. The unstability of 1 seemed to be attributed to the presence of a cross-conjugated moiety including in the $C$ and $D$ rings. Accordingly, we planned to disconnect the target molecule (1) into two fragments (2) and (3) as revealed below, reconnect them, and fiñaly construct the cross-conjugated system in question. We describe herein the first total synthesis of the title target (ref. 3 ).

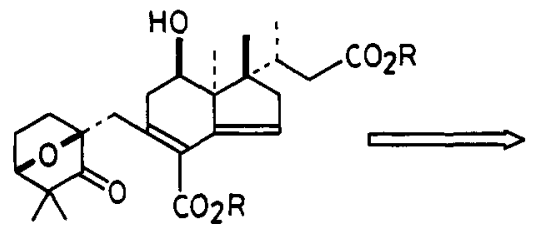

1. $\mathrm{R}=\mathrm{H}$

1a. $\mathrm{R}=\mathrm{CH}_{2} \mathrm{COC}_{6} \mathrm{H}_{4} \mathrm{Br}$<smiles>CC1(C)C(=O)C2(CI)CCC1O2</smiles>

2

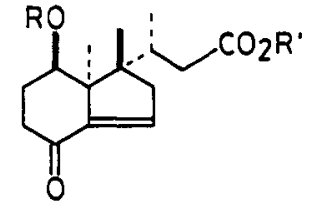

3

\section{CHIRAL SYNTHESIS OF THE A RING FRAGMENT}

The synthesis of the A ring part of 1 started with enzymatic reduction of 2,2-dimethylcyclohexane-1,3-dione (4) with baker's yeast (Scheme 1). The resulting (S) -2,2-dimethyl-3-hydroxycȳclohexan-1-one (5) (ref.4) (94.38 ee) was converted into the corresponding ethoxyethyl derivative ( $5 \mathrm{a})$, which on successive treatment with Bredereck's reagent (ref. 5) and with diisobutylaluminium hydride produced $\alpha, \beta$-unsaturated ketone $(6)$. The enone 6 was reduced with sodium trimethoxyborohydride, giving ally $\bar{I}$ alcohol (7) as a sole product which was transformed on acid hydrolysis into the $(+)$-olefinic cis-glycol (8). Treatment of 8 with $\mathrm{N}$-iodosuccinimide in acetonitrile (MeCN) in the därk effected smooth cyclization to give iodomethyl oxabicycloheptane alcohol (9), which on simple recrystallization afforded an optically pure sample. oxidation of 9 gave rise to $(1 \mathrm{R}, 4 S)-3,3-$ dimethyl-1-iodomethyl-7-oxabicyclo[2.2.1] heptan-2-one (2). This syñthesis involves 8 steps from 4 in $27.6 \%$ overall yield. Compound 2 was further reduced with sodium borohydride to

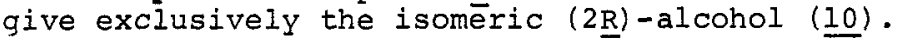


Scheme 1

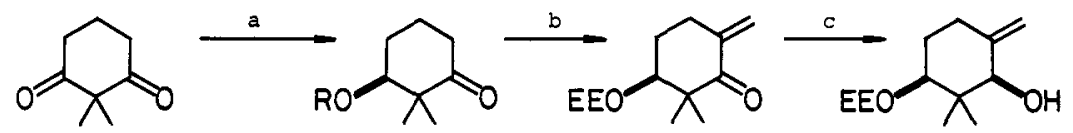

5. $\mathrm{R}=\mathrm{H}$

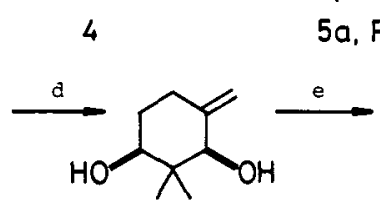

8

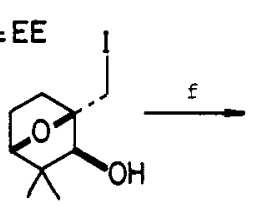

9

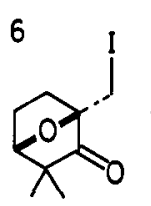

2

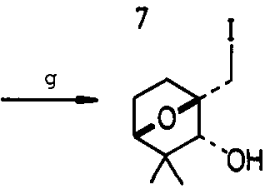

10

a) Baker's yeast, $\mathrm{D}-\mathrm{glucose}, \mathrm{KH} \mathrm{PO}_{4}, \mathrm{MgSO}_{4}$ aq $\mathrm{DMF}, 24{ }^{\circ} \mathrm{C}, 72 \mathrm{~h} ; \mathrm{EtOCH}=\mathrm{CH}_{2}$,

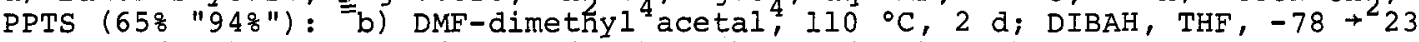
${ }^{\circ} \mathrm{C}$, I h (638): c) $\mathrm{NaBH}(\mathrm{OMe})$ (878): d) $\mathrm{HCl}(998):$ e) NIS, MeCN, $20^{\circ} \mathrm{C}, 16$ h $(798)$ : f) Jones oxid. (988): g) $\mathrm{NaBH}_{4}(948)$.

\section{STEREOSELECTIVE CONSTRUCTION OF THE C/D RING FRAGMENT}

The synthesis of another fragment 11 , corresponding to the $C$ and $D$ ring moiety of $\underline{1}$, commenced with $(\underline{R})-(-)$-carvone $(\underline{12})$ and involved stereoselective constrūction of four succēssive chiral centers as the key steps (Scheme 2). Nucleophilic/electrophilic carba-condensation of 12 proceeded smoothly with high stereoselectivity, giving a dialkylated compound 13 , which underwent annelation to yield an $\alpha, \beta$-unsaturated octalone 14. Difficulty was encountered with introduction of the methyl group into an angular position of 14 by 1,4 -conjugate addition with methylcuprate complexes under various conditions, owing to severe steric hindrance around the relevant reaction site, mainly due to the adjacent neopentyl group. This C-l unit introduction was achieved by the hydrocyanation procedure as follows. Hydrocyanation of 14 under kinetic conditions (ref. 6) effected predominant formation (63\%) of the desired cis-cyano ketone 15, accompanied by its trans isomer $15 \mathrm{a}$ (30\%) (ref. 7). The configuration of these ketones was confirmed by the $\overline{x-r a y}$ crystallographic analysis of 15 (ref. 8), indicating that stereoselective introduction of the four asymmetric centers has been completed as anticipated. Compound 15 was transformed by a usual several step sequence into decalone, which was oxidized with peroxytrifluoroacetic acid into $\varepsilon$-caprolactone 16 and then submitted to ring opening in a three-step process to give methoxycarbonyl acetate 17 . Cleavage of the two methoxyl groups of 17 was effected according to the $\overline{F u j i}$ procedure (ref. 9) to yield triol monoacetate 18, which on tritylation and oxidation afforded acetoxycyclohexanone trityl ether 11 .

\section{Scheme 2}<smiles>C=CC[C@]1(C)C(=O)C[C@H](C(=C)C)C[C@H]1C</smiles>

12
13<smiles>C=CC[C@]1(C)C2=CC(=O)CCC2C(C(=C)C)C[C@H]1C</smiles>

14<smiles>[R]C12CC(=O)CCC1C(C(=C)C)C[C@@H](C)[C@]2([R])CC=C</smiles>

15. $R=\alpha-C N$

15a, $R=B-C N$

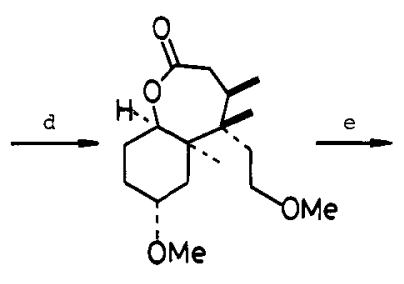

16

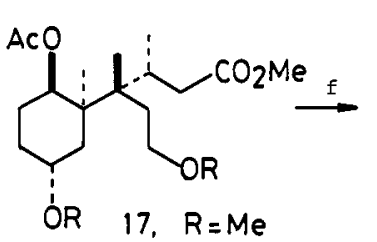

18. $\mathrm{R}=\mathrm{H}$<smiles>[CH]O[C@H]1CCC(=O)C[C@@]1(C)[C@@](C)(CCBr)C(C)CC(C)=O</smiles>

11

a) MeLi, $\mathrm{CuI}, \mathrm{Bu}_{3} \mathrm{P}, \mathrm{THF},-78{ }^{\circ} \mathrm{C}, 1 \mathrm{~h}$ and $-40{ }^{\circ} \mathrm{C}, 4 \mathrm{~h}$; HMPA, allyl bromide, -78 $+23{ }^{\circ} \mathrm{C}, 15 \mathrm{~h}(78 \%):$ b) LDA, MeCOC(TMS) $=\mathrm{CH}_{2} ; \mathrm{NaOMe}(74 \%):$ c) HCN, Et $\mathrm{H}_{3} \mathrm{Al}^{\prime}$ $\mathrm{THF}, 23{ }^{\circ} \mathrm{C}, 30 \mathrm{~h}$ : d) $\mathrm{OsO}_{4}$, NMO; $\mathrm{NaIO}_{4} ; \mathrm{NaBH} 4 \mathrm{MeI}, \mathrm{NaH} ; \mathrm{DIBAH} ; \mathrm{NH}_{2} \mathrm{NH}_{2} \cdot \mathrm{H}_{2} \mathrm{O}$,

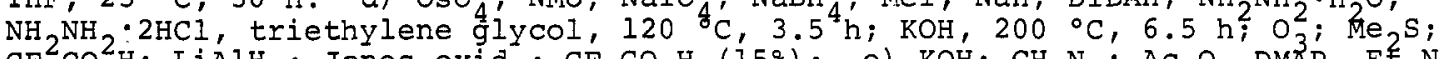
$\mathrm{CF}_{3} \mathrm{CO}_{3}^{2} \mathrm{H}$; LiAlH ; Jones oxid.; $\mathrm{CF}_{3} \mathrm{CO}_{3} \mathrm{H}(15 \%):$ e) $\mathrm{KOH} ; \mathrm{CH}_{2} \mathrm{~N}_{2} ; \mathrm{AC}_{2} \mathrm{O}, \mathrm{DMAP}^{3}, \mathrm{EE} \mathrm{N}^{\mathrm{N}}$;

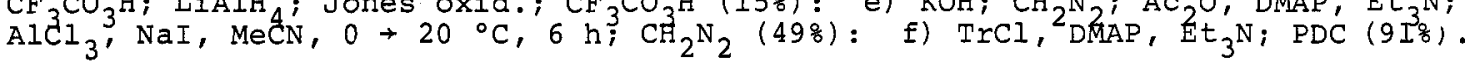




\section{COUPLING OF THE A AND C/D RING FRAGMENTS LEADING TO SYNTHESIS OF GLYCINOECLEPIN A}

The next phase of synthesis was the combination of the two fragments 10 and 11, one of the most critical steps of the synthesis. After many fruitess attempts, we hoped to submit these compounds to an intramolecular coupling. Thus (Scheme 3), treatment of 11 with the bromomagnesium thioureide-carbon dioxide complex (ref. 10), resulted in $\alpha$-carboxylation to yield $\beta$-ketocarboxylic acid, which was immediately reacted with 10 in the presence of dicyclohexyl carbodiimide to afford B-keto ester 19. Further reaction of 19 with potassium fluoride in MeCN in the presence of $\overline{18}-\mathrm{crown}-6$ at $65^{\circ} \mathrm{C}$ effected the relevant coupling between $C(9)$ and $C(19)$, giving $\delta$-lactone 20 in high yield (ref. 11). The lactone 20 , when treated with sodium allyloxide and then oxidized, was transformed into $\beta$-keto ester 21 , which was submitted to detritylation with acid and subsequent oxidation to afford 22 . Treatment of 22 with potassium $t$-butoxide in dimethoxyethane gave rise to the corresponding aldol, which was immediately dehydrated with 2-fluoropyridinium tosylate (ref. 12) to afford enone 23 . The allyloxycarbonyl group of 23 was then removed according to the procedure of Tsuji (ref. 13), giving the relevant dienol, which was treated immediately with sodium hydride and phenyl triflimide (ref. 14) to yield the corresponding dienyl triflate 24 in a high overall yield. The stage was now set to introduce the necessary one-carbon unit at the $C(8)$ position of 24 . This was accomplished by a modification of the ortar method (ref. 15). Compound 24, when treated with tributylamine, palladium acetate, and 1,1'-bis (diphenylphosphino) ferrocene in a large excess of water in $\mathrm{N}, \mathrm{N}$-dimethylformamide under a carbon monoxide balloon at $95^{\circ} \mathrm{C}$ for $3.5 \mathrm{~h}$, was Erānsformed into acetoxyl dicarboxylic acid 25 in $42 \%$ yield ( $82 \%$ based on the recovered 24). There is no experimental evidence available to detail how the compound $\overline{25}$ was produced under these conditions. Compound 25 was then saponified and esterified smoothly to give the corresponding bis (p-bromophenacyl) ester alcohol. The ester thus obtained was identical in every respect $\left({ }_{H}\right.$ NMR, IR, MS, CD, HPLC) with la, derived from the natural sample. The hatch-stimulating activity of the synthetic sample 1 was found to be indistinguishable from that of the natural sample (ref. 16).

\section{Scheme 3}

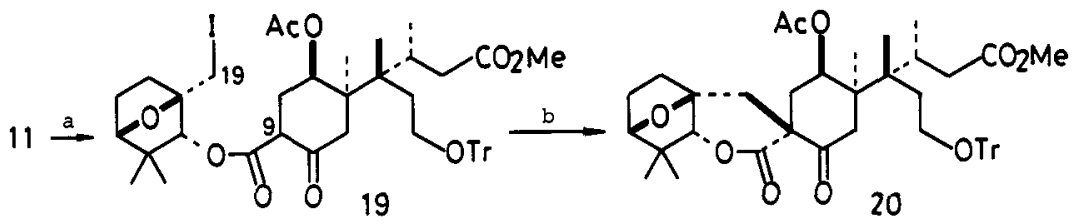

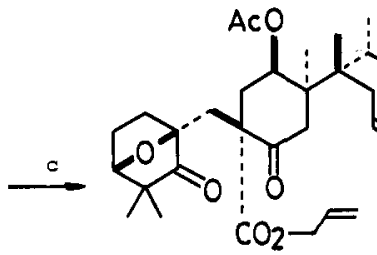

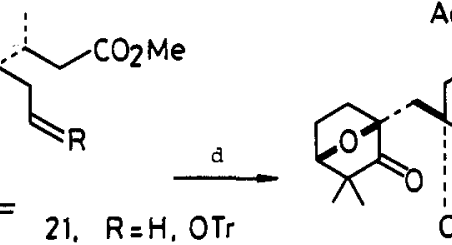

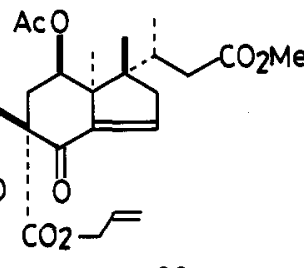

22. $R=0$

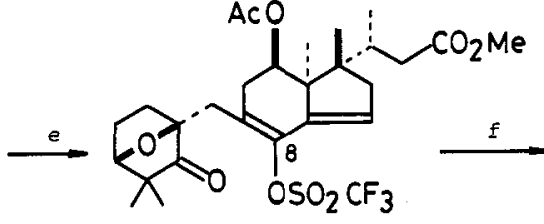

24

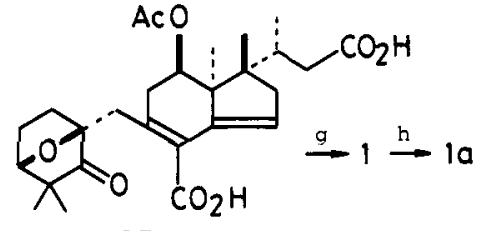

25

a) bromomagnesium thioureide- $\mathrm{CO}_{2}$ complex, DMF, $20{ }^{\circ} \mathrm{C}, 20 \mathrm{~h} ; 10, \mathrm{DCC}, \mathrm{DMAP}$, $\mathrm{CH}_{2} \mathrm{Cl}_{2}, 0 \rightarrow 20{ }^{\circ} \mathrm{C}, 20 \mathrm{~h}\left(84 \%{ }^{\prime} 90 \% "\right):$ b) $\mathrm{KF}$ (3 equiv), 18-crown-6-ether ( 3 equivf, MeCN, $65^{\circ} \mathrm{C}, 15 \mathrm{~h}\left(76{ }^{\circ}\right.$ "94\%"): c) sodium allyloxide; Swern oxid.; PTS; Swern oxid. (66\% "82z"): d) $t-B u O K, D M E,-78{ }^{\circ} \mathrm{C} ; 2-\mathrm{FC}_{5} \mathrm{H}_{4} \mathrm{NMe}^{\circ} \mathrm{OTs}, \mathrm{Et}{ }_{3} \mathrm{~N}$, $\mathrm{CH}_{2} \mathrm{Cl}_{2}(548):$ e) $\mathrm{Pd}(\mathrm{OAC}){ }_{2},\left(\mathrm{C}_{6} \mathrm{H}_{5}\right){ }_{3} \mathrm{P}, \mathrm{HCO}_{2} \mathrm{H}, \mathrm{Et}_{3} \mathrm{~N}, \mathrm{THF} ;\left(\mathrm{CF}_{3} \mathrm{SO}_{2}\right)_{2} \mathrm{NC}_{6} \mathrm{H}_{5}, \mathrm{NaH}$

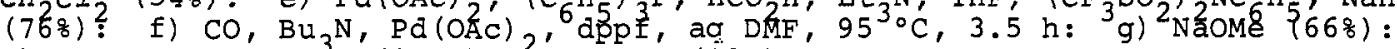
h) $\mathrm{p}^{-\mathrm{BrC}_{6} \mathrm{H}_{4} \mathrm{COCH}_{2} \mathrm{Br},(\underline{i}-\mathrm{Pr})}{ }_{2} \mathrm{NEt}, \operatorname{MeCN}(998)$. 


\section{REFERENCES}

1. T. Masamune, M. Anetai, M. Takasugi, and N. Katsui, Nature (London), 297, 495 (1982); T. Masamune, M. Anetai, A. Fukuzawa, M. Takasugi, H. Matsue, K. Kobayashi, S. Ueno, and N. Katsui, Bull. Chem. Soc. Jpn., 60, 981 (1987).

2. A. Fukuzawa, A. Furusaki, M. Ikura, and T. Masamune, J. Chem. Soc., Chem. Commun., 222, $748(1985)$; T. Masamune, A. Fukuzawa, A. Furusaki, M. Ikura, H. Matsue, T. Kaneko, A. Abiko, N. Sakamoto, N. Tanimoto, and A. Murai, Bull. Chem. Soc. Jpn., 60, 1001 (1987).

3. A. Muraí, N. Tanimoto, N. Sakamoto, and T. Masamune, J. Am. Chem. Soc., 110,1985 (1988).

4. K. Mori and H. Mori, Tetrahedron, 4l, 5487 (1985).

5. Cf., H. Bredereck, G. Simchen, S' Rebsdat, W. Kantiehner, P. Horn, R. Wahi, H. Hoffman, and P. Grieshaber, Chem. Ber. ' 101,41 ' (1968).

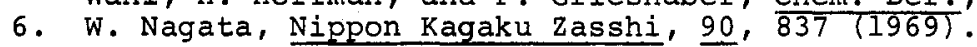

7. Treatment of $15 \mathrm{a}$ with $t-\mathrm{BuOK}$ in $t-\mathrm{BuOH}^{\prime}$ under reflux for $1.5 \mathrm{~h}$ led to recovery of 14 in $81 \%$ yièld.

8. The intensity measurements were performed by Dr. A. Furusaki, Hokkaido University, at the High Brilliance X-ray Laboratory of Hokkaido Universi-

9. M. Node, K. Ohta, T. Kajimoto, K. Nishide, E. Fujita, and K. Fuji, Chem.

10. Pharm. Bul1.' 31,4178 (1983). Yatsumura, N. Asai, and S. Yoneda, J. Chem. Soc., Chem. Commun., 1487 (1983).

11. Attempted intramolecular cyclization of the corresponding isomeric $\beta-$ ketoester, prepared from 9 and 11 , led to failure.

12. T. Mukaiyama, Angew. Chem., Int. Ed. Engl., 18, 707 (1979).

13. J. Tsuji, M. Nisar, and I. Shimizu, J. Org. Chem., 50, 3416 (1985).

14. J. B. Hendrickson and R. Bergeron, Tetrahedron Lett.' 4607 (1973); J. E.

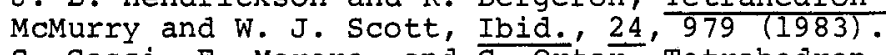

15. S. Cassi, E. Morera, and G. Ortar,' Tetrahedron Lett., 26, 1109 (1985).

16. Studies on the biological activity were carried out by Dr. A. Fukuzawa, Hokkaido University. 